\title{
Problems in Grammatical Structure: A Case Study of B.Ed. Student at the Education
}

\author{
Department \\ * Dr. Gulzar Ahmed, Assistant Professor \\ ** Dr. Syed Shafqat Ali Shah, Assistant Professor \\ *** Dr. Muhammad Nisar, Principal (Corresponding Author)
}

\begin{abstract}
English grammar is how words in the English language are translated into text. This includes the structure of words, phrases, clauses, and phrases, up to and including full-text structure. The main objective of the authors is to discover the difficulties of grammatical structures for students at the Department of Teacher Education. Shikarpur Shaikh Ayaz University. The students of B.Ed. undergraduate level of education department was selected as a data population. The fifty students were randomly selected from the education department. There is quantitative research underway. The researchers used a testing tool for a questionnaire. The student's collected data were analyzed by SPSS-Descriptive statistics. Some of the challenges and problems are facing during the English Grammar lesson of B.Ed. students. The students have used the conditional verb and also the proper use of a phrasal verb that is one of the problems with students. The use of an article is also one of the fundamental problems for undergraduate students. Teachers should make it possible for students to practice these materials either through activity-based teaching or through the CLT method so that they can be more attentive to EFL learning and not focus on translation alone.
\end{abstract}

Keywords: English, Grammar, Article, Verb, Preposition

Introduction

English is an overall language given its significance. It's appropriate for all the elements of the current world as 'the most commonly used term.' In reality, English is the science and developmental language. No other language provides such a large extent as English for valid examinations and studies. In all humanistic systems, it offers us a wealth of data. It is the language of the world to understand the lifestyles of different nations. It is the word of the arbitrators of the world. Understand the different countries' lifestyles. It is the expression of the arbitrators of the planet. We can't talk about the world without it. By then, English would worship the best of the planet's thoughts and compositions. Every positive information is power as well; English is power today. To focus upon the fundamental essence and accommodation of English, its assessments are to be regularized and promoted across the country at all levels (Larik, 2006).

Grammar is a key language feature. Mastering a language's grammar will affect language competency mastery. Therefore, grammar is a subject that should be studied in depth when studying language formally. Students must be provided with adequate grammar to have good language skills (Ellis,2009)

Grammar is a complicated and unattractive subject for many students. Students don't like grammar, and students can't get good results from learning it. Also, students who have been studying grammar at college for a few years still have a hard time making strong and correct sentences. Some students continue to make grammar errors when writing their degree papers, and teachers must work hard to correct mistakes (Ellis,2009)

Yule (2006) claimed that grammar is the definition of the phrase and phrase structures by considering their order in a language Furthermore, Weaver express that grammar divides into two definitions, in addition to these definitions of grammar. Grammar is a summary of a language 's syntax, and grammar is a collection of rules or a prerequisite to use it (Weaver, 1996).

* Department of Teacher Education, Shaikh Ayaz University, Shikarpur, Sindh, Pakistan

Email: dr.gulzar@gmail.com

** Department of Education, University of Gujrat, Gujrat Email: syed.shafqat@uog.edu.pk

*** Model High School, Shakardarra, Kohat Email: nisarkust74@ gmail.com 


\section{Background of the Study}

English is a Germanic language of the Indo-European family. It came from the British Island with two invading tribes, the Angles and the Saxons. That's why it was first called the "Anglo- Saxon language". Thus, old English, as we call it today, was the raw material for our modern English. It remained the language of England from $450 \mathrm{AD}$ to $1150 \mathrm{AD}$. Later on, Normans changed its shape almost completely and by the middle of 14 century, it became a mixture of regional dialects. It was spoken mostly in and around London, and therefore, was known as "Middle English". The English language developed very fastly in the latter half of 15 century, and within a century it became capable of expressing all human feelings. The English of London became a standard for the whole county. Two great English poets, Chaucer and Gower used this language, and thus, it became popular also as a written language. As there was no foreign invasion in England, this language continued to develop until it reached the stage of early Modern English of Shakespeare's time. After a few years, it became Modern English that we use nowadays. As a result of these interchanges, the vast majority of the nations of the world are getting bilingual. As Crystal, (2003) pointed, "a large portion of the people right currently call themselves speaker of at any rate two vernaculars".

English is holding a place of prestige in Pakistan. It is an essential language. It is the result of the constant efforts of English-speaking writers and scientists who have produced an amazingly large number of books in every faculty of Arts, Science and Culture during the last few centuries. This significance has been expressed in English, thanks in part to British dominance over most of the world and in part to the increasing global presence of the USA. As Dewey (2006) pointed out, "man uses language to convey assumptions and attitudes and to develop, compose, and control the relationship with others".

The success of a nation depends on education. The success of an individual or a state is always impossible without having access to proper education. Education has always resulted in the rise and fall of an individual as well as a state. The government always tries to allocate a major part of the budget in education just for the objective and purpose to ensure the growth and economy of a nation.

According to Mueen (2006) In Pakistan, the numbers of schools and colleges and universities have increased and it has increased in the rise of the literacy rate. New students are enrolled in schools, colleges, and universities these days which is the main focus of the government. Our country produces a great number of degree holders every year but still, a large number of students leave their schools, colleges, and universities because they fail certain subjects. Failing English subjects usually results in leaving their schools and saying farewell to their schools, colleges, universities, and education career. In numerous nations, English is no official language; as of today, English is often learned as a second language throughout the world. The global status of English has shifted suggestions to improve and educate English. As the quantity of non-local speakers surpasses the number of local speakers showing English as a second language (ESL) or unknown dialect (EFL), in this manner, has changed hugely in recent decades on account of its job as a language for worldwide contact. Educational programs, showing strategies, and instructing materials have been created to meet the changing needs of the ESL/EFL populace (Scheffler, 2011).

As demonstrated by Rehman (2008) express that English has become the most notable language on the planet. English is also a compulsory subject in all the educational institutes. All the exams like PMS, PCS, etc. are conducted in the English language and the test of every subject has its English marks of English grammar and composition. It is also treated as a medium of instruction in schools, colleges, and universities. educational institutes.

English has been a compulsory subject from the initial days, taught to the students, till graduation. In our education system, nobody can deny the role of English. It is the most focused subject in the list of topics in the syllabi. It is not taught as a means of communication but the majority of the time, students memorize the topics and pass their exams till matric. All other subjects are taught in the English language after matric and students face so many problems over here. It should not be dealt with as a compulsory subject, however, an important topic for the understanding of all other topics should be considered. In our education, English thus has a very important position. (Harmer, 2007). 
English is a compulsory subject and is taught as a subject in our schools, colleges, and universities. It is treated the same as physics, maths, chemistry, and biology. It should be treated as a language which should be used for the various purposes of communication as well as for our daily routine activities. Language learning is a continuous process and anyone interested in learning a language must practice four skills: listening, reading, speaking, and writing. English language should be used as a tool or a medium of learning and should not be mistreated because students would be having problems with the understanding of other subjects as well (Ahmad, 2007).

\section{The Importance of English}

The importance of the English language is very unprecedented. English is the language of England just as of the wide area and settlements related to the British Empire, and it is in like manner the language of the United States. Spoken by more than 260 million people, it is in the numbers who talk the greatest of the occidental lingos. English talking people contain around one-tenth of the all-out masses. English, nevertheless, isn't the greatest language on earth (Gerry, 2004).

As demonstrated by Tahir (2008), portray the importance of language isn't just a single a matter of numbers or space; it in like manner depends upon the centrality of people who talk it. The criticalness of language is unavoidably related in the mind of the world with the political imagined by the nations using it in their effect in all-inclusive issues, with the conviction people feel in their budgetary position and the sureness with which they meet their responsibilities, with their promise to the material and significant headway of the world. English is the Elementary language of the nations whose joined political effect, money related ampleness, business works out, social flourishing, and sensible and social duties to human advancement give stunning assistance to its numerical need (Long, and Doughty, 2011).

\section{Statement of the Problem}

English is an indispensable language for all and various both at national and international levels but still, most of the students fail in this subject in our country. The purpose of this analysis is therefore to identify B.Ed. 's problems. Shaikh Ayaz University of Shikarpur English Students at the Department of Teacher Education.

\section{Significance of the Study}

Education is the basic right of society as a whole. To be able to communicate internationally and to transform knowledge, bilingual people like Pakistanis have to study major foreign languages. Although it was not yet recognized as a leading language in an international field by the people of the subcontinent. As a developing country, we should not slip into a glorified view that in all respects we are self-sufficient. The Committee on National Education endorsed this view. Most times English will continue to be efficient methods of communication with the outside world and the most powerful source of data on science and innovation in the latest growth., in this manner, all understudies ought to have sound information on this language. The researcher has selected the Department of Teacher Education, the Shaikh Ayaz University of Shikarpur for the research where the data has been collected from the students.

\section{Objectives of the Study}

The following were the main objectives of the study:

1. To find out how English grammatical structures are being taught in the B.Ed. level.

2. To Identify problem areas in the teaching and learning English grammatical structures in the

\section{Hypothesis}

$$
\text { B.Ed. level and to proffer solutions to such identified problems. }
$$

The following were the main hypothesis of the study:

i. That student in the B.Ed. the level shows a non-challenge mentality to the learning of English grammatical structures because of its principles and details.

ii. That a few instructors use strategies that are unseemly and insufficient for student's

\section{Methodology} appreciation in the educating of English grammatical structures.

The methodology is the main theoretical foundation of the current research. This is a quantitative method research in which there is a descriptive analysis of the data collected from the students at the Department of Teacher Education, Shaikh Ayaz University of Shikarpur. The researcher collected 
data from the concerned students who are studying at the departments. The target population consists of both males and females that are randomly selected for the collection of the data.

\section{Data Collection Procedure}

As a testing tool, the researcher has selected the questionnaire. The main aim is to collect the data from the students at the Department of Teacher Education, Shaikh Ayaz University of Shikarpur

\section{Data Collection sources}

The following are the tools for data collection.

\section{Primary Source}

The primary data for the research is the questionnaire collected from the students at the Department of Teacher Education, Shaikh Ayaz University of Shikarpur

\section{Sample and Population}

For the collection of data through questionnaires, the random sampling technique is used.

\section{Population}

The B.Ed. students of Shaikh Ayaz 's University of Shikarpur 's Department of Teacher Education level became the data population.

\section{Sample}

50 students from the department have been randomly selected to collect the data.

\section{Data Analysis Procedure}

This part deals with the whole procedure of the analysis. SPSS- Descriptive Statistics analyzed the data collected from the students. Thus, the findings and suggestions will be generalized from the collected data.

\section{Results and Discussion}

The data collected from the student was analyzed through SPSS- Descriptive statistics. Following is the analysis and interpretation of the data.

Table 1: Article

\begin{tabular}{cccccc}
\hline \multicolumn{5}{c}{ Article } \\
\hline \multirow{4}{*}{ Valid } & Frequency & Percent & Valid Percent & $\begin{array}{c}\text { Cumulative } \\
\text { Percent }\end{array}$ \\
& Correct & 16 & 32 & 32.0 & 32.0 \\
& InCorrect & 34 & 68 & 68.0 & 100.0 \\
& Total & 50 & 100.0 & 100.0 & \\
\hline
\end{tabular}

The usage of the article is also one of the basic problems for the students at the undergraduate level. The data collected from the students indicates that the majority of the students are unable to use articles appropriately, while the very least number of students know the usage of articles. It indicates that usage of the article is one of the basic problems that need to be given attention so that the students don't commit any mistakes onwards.

Table 2: Preposition

\begin{tabular}{cccccc}
\hline \multicolumn{5}{c}{ Preposition } \\
\hline \multirow{4}{*}{ Valid } & Frequency & Percent & Valid Percent & $\begin{array}{c}\text { Cumulative } \\
\text { Percent }\end{array}$ \\
& Correct & 22 & 44 & 44.0 & 44.0 \\
& InCorrect & 28 & 56 & 56.0 & 100.0 \\
& Total & 25 & 100 & 100.0 & \\
\hline
\end{tabular}

The correct usage of prepositions is also one of the problems for students at B.Ed. level. The data collected from the students indicates that the majority of the students are unable to use preposition appropriately, while the very least number of students know the usage of the preposition. It indicates that usage of the preposition is one of the basic problems that need to be given attention so that the students don't commit any mistakes onwards. 
Table 3: Phrasal verb

\begin{tabular}{cccccc}
\hline \multicolumn{5}{c}{ Phrasal verb } \\
\hline \multirow{4}{*}{ Valid } & Frequency & Percent & Valid Percent & $\begin{array}{c}\text { Cumulative } \\
\text { Percent }\end{array}$ \\
& Correct & 20 & 40 & 40.0 & 40.0 \\
& InCorrect & 30 & 60 & 60.0 & 100.0 \\
& Total & 50 & 100 & 100.0 & \\
\hline
\end{tabular}

The correct usage of a phrasal verb is also one of the problems for students at B.Ed. level. The data collected from the students indicates that the majority of the students are unable to use phrasal verb appropriately, while the very least number of students know the usage of a phrasal verb. It indicates that usage of a phrasal verb is one of the basic problems that need to be given attention so that the students don't commit any mistakes onwards.

Table 4: Conditional verb

\begin{tabular}{cccccc}
\hline \multicolumn{5}{c}{ Conditional verb } \\
\hline \multirow{4}{*}{ Valid } & Frequency & Percent & Valid Percent & $\begin{array}{c}\text { Cumulative } \\
\text { Percent }\end{array}$ \\
& Correct & 20 & 40 & 40.0 & 40.0 \\
& Incorrect & 30 & 60 & 60.0 & 100.0 \\
& Total & 25 & 100 & 100.0 & \\
\hline
\end{tabular}

The correct usage of the conditional verb is also one of the problems for students at B.Ed. level. The data collected from the students indicates that the majority of the students are unable to conditional verb appropriately, while the very least number of students know the usage of a phrasal verb. It indicates that usage conditional verb is one of the basic problems that need to be given attention so that the students don't commit any mistakes onwards.

Table 5: Voice

\begin{tabular}{|c|c|c|c|c|c|}
\hline \multicolumn{6}{|c|}{ Voice } \\
\hline & & Frequency & Percent & Valid Percent & $\begin{array}{c}\text { Cumulative } \\
\text { Percent }\end{array}$ \\
\hline \multirow[t]{3}{*}{ Valid } & Correct & 12 & 24 & 24.0 & 24.0 \\
\hline & Incorrect & 38 & 76 & 76.0 & 100.0 \\
\hline & Total & 25 & 100 & 100.0 & \\
\hline
\end{tabular}

The correct usage of voices is also one of the problems for students at B.Ed. level. The data collected from the students indicates that the majority of the students are unable to voices appropriately, while the very least number of students know the usage of voices. It indicates that a usage voice is one of the basic problems that need to be given attention so that the students don't commit any mistakes onwards.

\section{Conclusion}

From the data collected from the students, it is observed that the correct usage of voices is also one of the problems for students at B.Ed. level.

1. The use of the essay is also one of the basic problems for undergraduate students. The data obtained from the students show that most students are unable to use papers properly while very few students know the use of papers. It shows that article use is one of the fundamental problems to be considered to avoid mistakes by students.

2. The proper use of prepositions is also an issue for B.Ed. students. level. The data collected from the students show that most students do not use preposition properly, while a minimum number of students know the use of the preposition. This says that the use of prepositions is one of the fundamental issues that need to be discussed in order not to make errors.

3. One of the problems for students of B.Ed. is the correct use of the phrasal verb. The students' collected data shows that most students do not use phrasal verbs properly, whereas very few 
students know the use of phrasal verbs. It says the use of the phrasal verb is one of the fundamental problems which must be solved so that students make no mistakes.

4. The right use of the conditional verb is also an issue for B.Ed. students, level. The student's data suggests that most students are unable to use the verb properly, while the least number of students know the use of the verb phrase. It shows that the use of a conditional verb is one of the fundamental problems to be addressed for students not to make mistakes.

5. The data from students show that most students cannot speak adequately, while the least number of students are aware of the use of voices. It indicates that the use of the voice is one of the fundamental problems to be addressed for the students not to commit errors.

\section{Recommendations}

1. The use of the article is also one of the basic problems for undergraduate students. Therefore, it is recommended that teachers should make the students practice these materials either using activity-based teaching or by a direct method so that they are more attentive to EFL learning than just translation.

2. The proper use of prepositions is also an issue for B.Ed. students. So, it is recommended teachers should make the students practice these materials either using activity-based teaching or by a direct method so that they are more attentive to EFL learning than just translation.

3. One of the problems for students of B.Ed. is the correct use of the phrasal verb. Therefore, it is recommended that teachers should make the students practice these materials either using activity-based teaching or by a direct method so that they are more attentive to EFL learning than just translation.

4. The Right use of the conditional verb is also an issue for B.Ed. students. So, it is recommended Teachers should make the students practice such materials either through activity-based teaching or through the direct method so that they could be more attentive to the learning of EFL not to focus on only translation.

5. The right use of voices is also a concern for B.Ed students. Therefore, it is recommended that teachers should make the students practice these materials either using activity-based teaching or by a direct method so that they are more attentive to EFL learning than just translation.

\section{References}

Ahmad, J.S. (2007). English Language Teaching in Pakistan. Pub. Majeed Press. P.34

Brinton, L. J. (2000). The structure of modern English: A linguistic introduction. John Benjamins Publishing.

Crystal, D. (2003). English as a global language (2nded.). Cambridge: Cambridge University Press.

Dewey, M. (2006). English as a lingua franca: An empirical study of innovation in lexis and grammar. Unpublished Ph.D. thesis, King's College London.

Ellis, R. (2009). Implicit and explicit knowledge in second language learning, testing and teaching (Vol. 42). Multilingual Matters.

Garrett, H.E. (1997). Statistics in Psychology and Research in Education, $6^{\text {th }}$ ed. Combine Printers Pvt. Ltd, Lahore. Pakistan.

Gerry, P. (2004). The teaching of English as a Foreign Language. Organization of the United Nations Rome, Italy.

Harmer, J. (2007). How to teach English. London: Pearson Education Limited.

Larik, K.M. (2006). English as an International Language. The Daily Dawn Karachi. April 24, 1986.

Long, M. H., \& Doughty, C. J. (Eds.). (2011). The handbook of language teaching (Vol. 63). John Wiley \& Sons.

Mueen. A. (2006) Teaching of Foreign Language, Bhatti Printing Corporation.

Rehman, K. (2008). Place of English in Pakistan. The Daily Dawn Karachi. Oct 7, 1985.

Scheffler, P. (2011). Rule difficulty: Teachers' intuitions and learners' performance. Language Awareness, 20, 221-237.

Tahir, (2008). Modern Approaches to Teaching English as a Second language. Pub. Mukhtar Ahmad.

Weaver. 1996. Teaching grammar in context. Heinemann. 1-2

Yule, G.2006. The study of a language. New York: Cambridge University Press. 74 